\title{
Liraglutide protects against high-fat diet-induced kidney injury by ameliorating apoptosis
}

\author{
Riying Liang ${ }^{1,2,3}$, Meijun Wang ${ }^{1,2}$, Chang Fu ${ }^{1,2}$, Hua Liang ${ }^{1,2}$, Hongrong Deng ${ }^{1,2}$, Ying $\operatorname{Tan}^{1,2}$, Fen $\mathrm{Xu}^{1,2}$ and \\ Mengyin Cai ${ }^{1,2}$ \\ 'Department of Endocrinology and Metabolism, The Third Affiliated Hospital of Sun Yat-Sen University, Guangzhou, China \\ ${ }^{2}$ Guangdong Provincial Key Laboratory of Diabetology, Guangzhou, China \\ ${ }^{3}$ Department of Ultrasound, Sun Yat-Sen Memorial Hospital, Sun Yat-Sen University, Guangzhou, China
}

Correspondence should be addressed to F Xu or M Cai: xufen3@mail.sysu.edu.cn or my.sabrina.c@163.com

\begin{abstract}
Background: Obesity is associated with the development and progression of chronic kidney disease. Emerging evidence suggests that glucagon-like peptide-1 receptor agonist could reduce renal damage and albuminuria. Sirtuin 1 (SIRT1) was considered as a crucial regulator in metabolism-related kidney disease. Herein, the role of SIRT1 in liraglutide-ameliorated high-fat diet (HFD)-induced kidney injury was illustrated. Methods: Male C57BL/6 mice were fed HFD for 20 weeks to induce kidney injury that was then treated with liraglutide for 8 weeks to estimate its protective effect on the kidney. Also, the mechanism of the drug in SV40 MES 13 (SV40) mouse mesangial cells was elucidated.

Results: Liraglutide treatment ameliorated HFD-induced metabolic disorders, including hyperglycemia, increasing body weight, and insulin resistance. In addition, kidney weight, urine albumin-to-creatinine, and kidney morphological changes such as vacuolated tubules, glomerulomegaly, thickened glomerular basement membrane, and tubulointerstitial fibrosis were also significantly ameliorated. Furthermore, apoptotic cells and apoptosis markers were downregulated in the kidney of liraglutide-treated mice. In addition, the expression of SIRT1 protein was upregulated, whereas thioredoxininteracting protein (TXNIP), which serves as a mediator of oxidative stress and apoptosis in metabolism disease, was downregulated by liraglutide. In SV40 cells, the effect of liraglutide on reversing the upregulation of cleaved caspase-3 induced by high glucose (30 mM) was hampered when SIRT1 was knocked down; also, the downregulation of TXNIP by liraglutide was blocked.

Conclusions: Liraglutide might have a beneficial effect on metabolism-related kidney damage by inhibiting apoptosis via activation of SIRT1 and suppression of TXNIP pathway.
\end{abstract}

\section{Key Words}

- chronic kidney disease

- glucagon-like peptide-1

- apoptosis

\section{Introduction}

Chronic kidney disease (CKD) is increasing worldwide, and obesity is a major risk factor for the development of CKD $(1,2)$ that could be independent of hypertension, diabetes, and dyslipidemia (3). The pathological features of obesity-related kidney damage include tubular hypertrophy, glomerular hypertrophy, thickening of the glomerular basement membrane, and mesangial matrix expansion $(4,5)$. These damages contribute to albuminuria and ultimately, tubulointerstitial fibrosis and glomerulosclerosis $(6,7)$. Despite the public

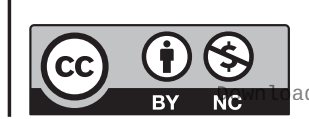

This work is licensed under a Creative Commons Attribution-NonCommercial 4.0 International License. ded from Bioscientifica.com at 04/26/2023 10:19:48AM 
health correlation between obesity and kidney injury, there is no effective drug therapy approved for kidney damage.

Glucagon-like peptide-1 (GLP-1) is mainly secreted from intestinal L cells. The circulating level of GLP-1 increases rapidly after food intake (8). GLP-1 receptor agonists (GLP-1RAs) have been developed for the treatment of type 2 diabetes mellitus (T2DM). GLP-1 receptor is found in various locations, such as preglomerular vascular smooth muscle, mesangial cells, and proximal tubular cells in the kidney $(9,10,11)$. Liraglutide, one of the GLP-1RAs, has 97\% amino acid sequence identity to human GLP-1. LEADER (Liraglutide Effect and Action in Diabetes: Evaluation of Cardiovascular Outcome Results A Long Term Evaluation) trial revealed that the liraglutidetreated group reduced the events of new persistent microalbuminuria and serum creatinine, end-stage kidney disease, and death from kidney disease as compared to the traditional diabetes treatment group in patients with T2DM and high cardiovascular risk (12). Mechanisms linking sustained GLP-1 receptor activation to renal protection include control of intense blood glucose level, blood pressure level, blood lipid level, and body weight and improvement of inflammation and fibrosis of the kidney (13). However, the exact mechanisms by which GLP-1 and its mimetics improve the renal function are not yet well understood.

Sirtuin 1 (SIRT1) is a subtype of sirtuins that play a vital role in maintaining the balance of blood glucose, blood lipid, and energy metabolism (14). The protective effects of SIRT1, such as regulation of energy metabolism, anti-fibrosis, and anti-oxidative stress, have been detected in various kidney disease models $(14,15,16)$. A previous study found that loss of SIRT1 led to severe apoptosis and fibrosis in the kidney in SIRT1 ${ }^{+/-}$mice as compared to wild-type mice after being subjected to ureteral obstruction (17). Previous studies have also shown that the proximal tubules-specific overexpression of SIRT1 enhances the remission of proteinuria caused by diabetes (18). Together, these findings indicate that SIRT1 is essential for renal protection. It has been reported to be reduced in various tissues, including the kidney, after exposure to a high-fat diet (HFD) (19). Nevertheless, the role of SIRT1 in the protective effects of liraglutide on kidney disease induced by HFD has not yet been evaluated. Herein, we used HFD-induced obese mouse model and SV40 mouse mesangial cells as an in vitro model to test the hypothesis that SIRT1 is a key pathway by which liraglutide contributes to the protective renal function in obesity-related kidney injury.

\section{Materials and methods}

\section{Animal studies}

Seven-week-old C57BL/6J male mice were purchased from the Model Animal Research Center (Nanjing, China) and housed in a $12 \mathrm{~h}$ light: $12 \mathrm{~h}$ darkness cycle. After 1 week acclimatization period, the animals were fed HFD $(60 \%$ calories from fat, Research Diets, New Brunswick, NJ, USA) for 20 weeks to induce kidney injury. Low-fat diet (11\% calories from fat, Guangdong Medical Laboratory Animal Center) was used as control. Then, the mice were divided into three groups, of which, one was treated with liraglutide (400 $\mu \mathrm{g} / \mathrm{kg} /$ day, Novo Nordisk A/S) by intraperitoneal injection for 8 weeks; the other two groups received saline as the normal control (NC) group. During the in vivo experiment, the data of body weight, 6-h fasting blood glucose (FBG) levels, and food intake of all mice were monitored every 2 weeks. At the end of the experiments, mice were fasted for $8 \mathrm{~h}$, anesthetized with isoflurane, and sacrificed to collect blood and tissue. All experiments were approved by the Animal Ethics Committees of the Sun Yat-sen University.

\section{Cell culture}

SV40 mouse mesangial cells were purchased from the Cell Bank of the Chinese Academy of Sciences (Shanghai, China) and cultured in normal glucose $(5.6 \mathrm{mmol} / \mathrm{L}$ D-glucose, Sigma-Aldrich) medium containing 5\% (v/v) fetal bovine serum (FBS), 3:1 mixture of DMEM and Ham's F12 medium, $14 \mathrm{mM}$ HEPES, $1 \mathrm{mmol} / \mathrm{L}$ sodium pyruvate, 100 units/mL penicillin, and $100 \mu \mathrm{g} / \mathrm{mL}$ streptomycin at $37^{\circ} \mathrm{C}$ in a humidified atmosphere of $5 \% \mathrm{CO}_{2}$. When the cells achieved 60-65\% confluency, the medium was changed to normal glucose (NG) concentration ( $5.6 \mathrm{mmol} / \mathrm{L}$ D-glucose) or high glucose (HG) concentration (30 mmol/L D-glucose) in the presence or absence of 1, 10, and $100 \mathrm{nmol} / \mathrm{L}$ liraglutide (Selleck, Houston, TX, USA) for $48 \mathrm{~h}$.

The cells were transfected with a lentiviral vector expressing the short hairpin (sh)RNA sequence of Sirt1 to knock down SIRT1 expression, while the control vector harbored a scramble sequence (GeneChem, Shanghai, China). SV40 cells were transfected with lentiviral vectors expressing the short hairpin (sh)RNA sequence of Sirt1 for $12 \mathrm{~h}$ to knock down SIRT1 expression, while the control vector carried a scramble sequence (GeneChem). Subsequently, the medium was changed, and the cells were cultured in normal glucose concentration for an additional $48 \mathrm{~h}$. Then, the transfected cells were treated 
with HG (30 $\mathrm{mmol} / \mathrm{L})$ and with or without liraglutide $(100 \mathrm{nmol} / \mathrm{L})$ as indicated for $48 \mathrm{~h}$.

\section{Intraperitoneal glucose tolerance test (IPGTT) and intraperitoneal insulin tolerance test (IPITT)}

To conduct IPGTT, mice were fasted overnight and then given glucose $(2 \mathrm{~g} / \mathrm{kg})$. After $4 \mathrm{~h}$ of fasting, animals were subjected to an IPITTat 0.75 units/kg of insulin (Novolin $\mathrm{R})$. Blood glucose was measured from the tail vein at 0 , 30, 60, 90, and 120 min post-intraperitoneal injection. ONETOUCH Ultra Vue glucometer (Johnson) was used in IPGTT and IPITT.

\section{Urine albumin-to-creatinine ratio (ACR)}

According to the protocol description, 24-h urine collection of mice was quantitatively measured using the mouse Albuwell M Kit (1011, Exocell, Philadelphia, PA, USA) and Creatinine Companion Kit (1012, Exocell).

\section{Western blot}

After homogenizing in RIPA buffer (Thermo Fisher Scientific), the protein of kidney tissues and mouse mesangial cells were collected by centrifugation at $20,817 \boldsymbol{g}$ for $20 \mathrm{~min}$ at $4^{\circ} \mathrm{C}$. The protein concentration was determined using a BCA kit (Thermo Fisher Scientific). Equivalent of protein was separated by $10 \%$ or $15 \%$ SDS-PAGE. Then, the polyvinylidene fluoride membranes were probed with primary antibodies for SIRT1 (1:500, Cell Signaling Technology), TXNIP (1:1000, Cell Signaling Technology), cleaved caspase-3 (1:500, Cell Signaling Technology), and Bcl-2 (1:500, Cell Signaling Technology) in Tris-HCl buffer saline with $5 \% \mathrm{BSA}$ at $4^{\circ} \mathrm{C}$ overnight, followed by incubation with secondary antibodies (1:10,000, DyLight 800; Thermo Fisher Scientific). The intensity of the immunoreactive bands was quantified using the Odyssey Infrared Imaging System (LI-COR Biosciences, Lincoln, NE, USA).

\section{Hematoxylin-eosin (H\&E) staining}

Fresh kidney tissues were fixed in $4 \%$ neutral-buffered formalin solution. Sections of $8 \mu \mathrm{m}$ thickness were collected on slides and processed by standard H\&E staining protocol.

\section{Periodic acid of Schiff-methenamine (PASM) staining}

Each group of paraffin sections was oxidized, fixed, washed, and examined according to standard procedures until a black precipitate appeared in the glomerular capillary basement membrane. Then, the sections were further observed and photographed with a BX63 microscope (Olympus) to reveal a black glomerular basement membrane.

\section{Masson trichrome staining}

The paraffin sections of each group were dewaxed, dehydrated, stained with hematoxylin, and rinsed with tap water. Subsequently, the sections were stained with a mixture of 1\% Ponceau (HL12202, Shanghai Haling Biotechnology Co. Ltd, Shanghai, China) and 1\% fuchsin solution (HPBIO-SJ820, Shanghai Hepeng Biotechnology Co., Ltd) before the reaction was terminated by a mixture of $1 \%$ glacial acetic acid and $1 \%$ molybdic acid solution, followed by counterstaining with a mixture of $1 \%$ brilliant green and $1 \%$ phosphomolybdic acid. Finally, the sections were observed under the microscope (BX63, Olympus) with original magnification $\times 20$, and the collagen fibers were found to be stained blue.

\section{Terminal deoxynucleotidyl transferase-mediated dUTP-biotin nick end labeling (TUNEL) assay}

Double-stranded, low molecular weight DNA and singlestrand breaks in high molecular weight DNA were identified by TUNEL assay (Roche), according to the manufacturer's protocol. About six to seven random fields of view for each kidney sample were examined and images acquired at a DM 2500B microscope (Leica Microsystems) with original magnification $\times 20$. TUNEL-positive cells were counted by Image $\mathrm{J}$ software.

\section{Statistical analysis}

Statistical analysis was performed using SPSS 24.0, and $P$-value $<0.05$ was considered significant. All values are expressed as mean \pm S.E.M. The two-tailed, unpaired Student's $t$-test was used to compare the differences between the two groups. ANOVA with Bonferroni comparison test was used to assess the statistical significance of differences among groups. Each experiment was repeated at least three times.

\section{Results}

Liraglutide decreased body weight and improved glucose homeostasis in HFD-challenged mice

The body weight and the FBG in the HFD mice increased significantly as compared to the NC group (Fig. 1A and B).

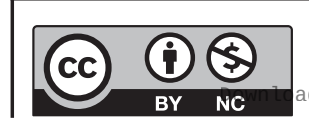

This work is licensed under a Creative Commons Attribution-NonCommercial 4.0 International License. ded from Bioscientifica.com at 04/26/2023 10:19:48AM 

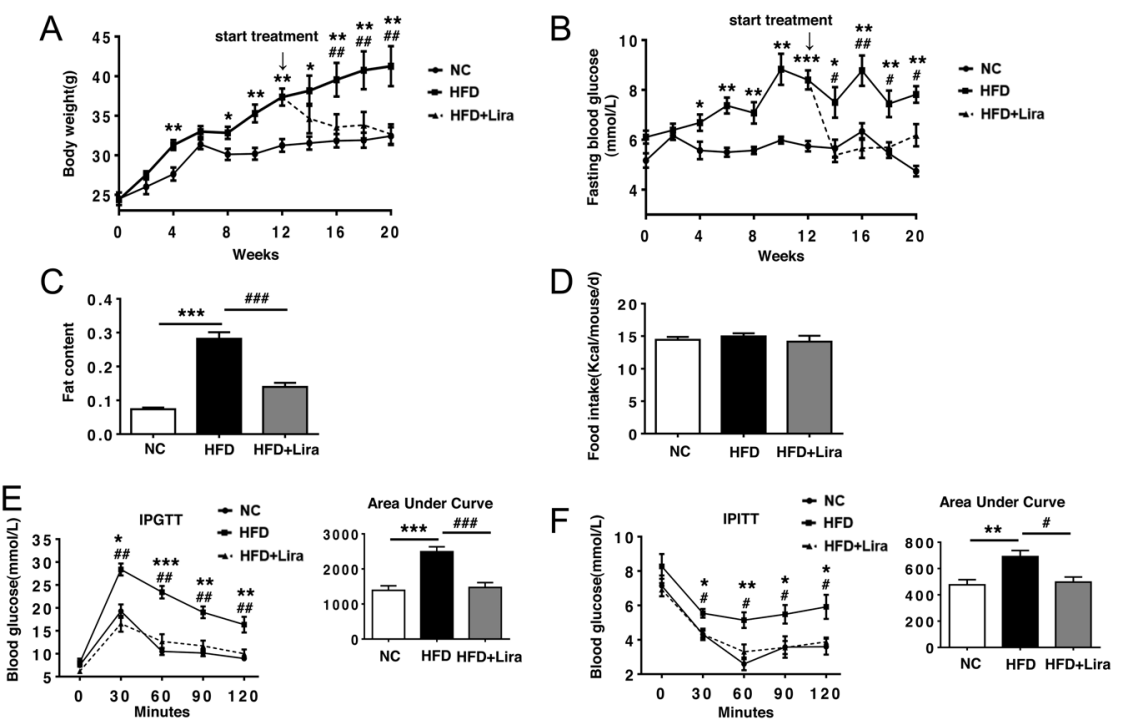

\section{Figure 1}

Liraglutide decreased body weight and improved glucose homeostasis in HFD-challenged mice. (A) Body weight during HFD feeding and liraglutide treatment every 2 weeks. (B) Fasting blood glucose during HFD feeding and liraglutide treatment every 2 weeks. (C) Fat content is determined by quantitative magnetic resonance. (D) Food intake during HFD feeding and liraglutide treatment. (E and F) Intraperitoneal glucose tolerance test $(E)$ and insulin tolerance test (F) were performed after 8 weeks of liraglutide intervention. The AUCs were determined. $\star P<0.05$ NC vs HFD; $* * P<0.01$ NC vs HFD; $\star * \star P<0.001$ NC vs HFD. $\# P<0.05$ HFD vs HFD + Lira; $\# P<0.01$ HFD vs HFD + Lira; $\# \# P<0.01$ HFD vs HFD + Lira. Values are mean \pm S.E.M. $(n=5-14)$. Lira, liraglutide.
After liraglutide treatment, body weight and FBG were significantly reduced as compared to that of HFD mice (Fig. 1A and B). Thus, it could be expected that at the end of the experiment, the fat content of the mice treated with liraglutide was significantly lower than that of HFD mice (Fig. 1C). In the current study, treatment with liraglutide decreased food intake as compared to the saline group; however, there was no significant change (Fig. 1D). To investigate whether liraglutide improved glucose metabolism, we performed IPGTT and IPITT after 8 weeks of liraglutide treatment. Strikingly, liraglutide improved glucose tolerance of HFD-induced mice, as indicated by the lower glucose levels at 30, 60, and $120 \mathrm{~min}$ as well as the significantly small area under the curve (AUC) value (Fig. 1E). During the IPITT test, administration of insulin after liraglutide treatment caused a significant decrease in blood glucose levels at 30, 60, and $120 \mathrm{~min}$ and the significantly small AUC value as compared to the HFD mice (Fig. 1F). Taken together, these data showed that liraglutide improves body weight, glucose tolerance, and insulin resistance in HFD-challenged mice.

\section{Liraglutide alleviated kidney weight, urine ACR, and kidney morphology changes induced by HFD}

At the end of the experiment, the kidney weight in HFDfed mice was significantly decreased after liraglutide treatment as compared to the saline control (Fig. 2A). The urine ACR of HFD mice was higher than that of NC mice, while liraglutide treatment significantly reduced the ACR (Fig. 2B). Moreover, the morphological changes in the kidney are also obvious. The vacuolated tubules and glomerulomegaly were dramatically improved in mice fed HFD by liraglutide treatment (Fig. 3C). In addition, PASM staining revealed that the thickened glomerular basement membrane was improved in the kidney of the HFDchallenged mice by liraglutide treatment, and Masson staining showed that the tubulointerstitial lesions of
A

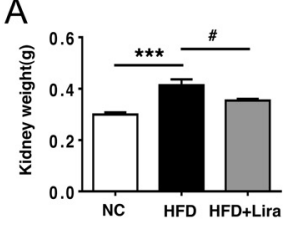

B

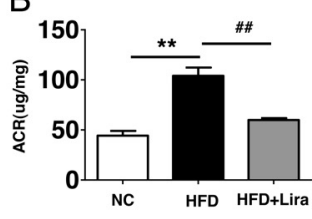

C
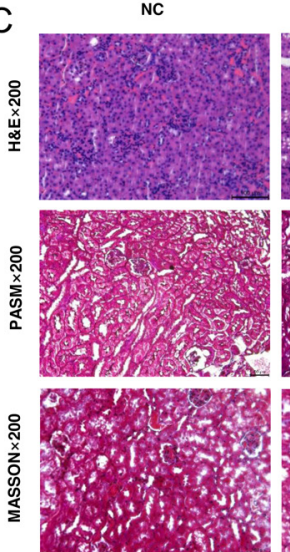

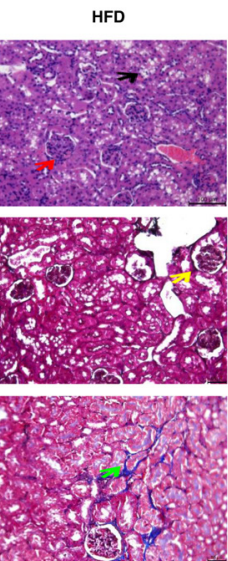

(c) 2020 The authors Published by Bioscientifica Ltd

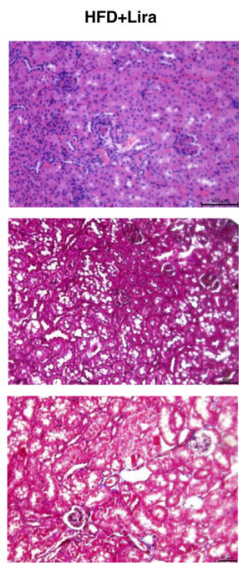

\section{Figure 2}

Liraglutide alleviated kidney weight, urine $A C R$, and pathological changes induced by HFD. (A) Kidney weight was improved after liraglutide intervention. (B) Urine ACR was ameliorated after liraglutide treatment. (C) Hematoxylin and eosin staining $(\times 200)$, PASM staining $(\times 200)$, and Masson staining $(\times 200)$ showed that lesions of vacuoles, distinct Bowman's glomerular capsule, thickened glomerular basement membrane, and lesions of tubulointerstitial fibrosis were ameliorated after liraglutide treatment. (black arrow) vacuoles in the tubular cells; (red arrow) glomerulomegaly; (yellow arrow) thickened glomerular basement membrane; (green arrow) tubulointerstitial lesions; Lira, liraglutide. https://ec.bioscientifica.com https://doi.org/10.1530/EC-20-0294
This work is licensed under a Creative Commons Attribution-NonCommercial 4.0 International License. ded from Bioscientifica.com at 04/26/2023 10:19:48AM 
A

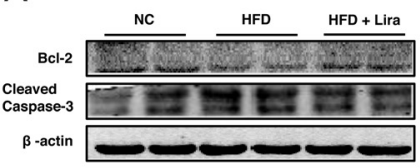

B

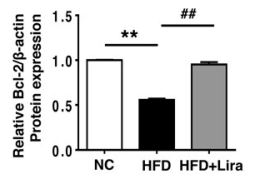

C
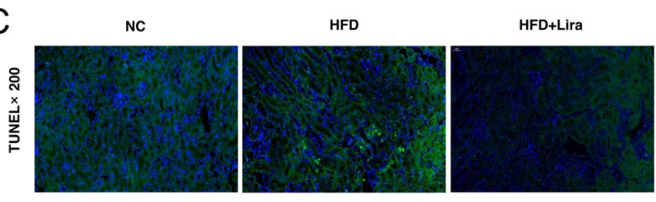

kidney in HFD-induced mice were alleviated by liraglutide treatment (Fig. 3C).

\section{Liraglutide alleviated apoptosis in the kidney of HFD-fed mice}

Increased apoptosis was observed in diabetic human kidney and mouse models with metabolism-related kidney disease (20). Bcl-2 is an inhibitor of apoptosis (21). The Bcl-2 protein level was decreased in the kidneys from HFD mice as compared to those from NC mice (Fig. $3 \mathrm{~A}$ and $\mathrm{B})$. The level of cleaved caspase-3 protein, a key executor of apoptosis (22), was significantly increased in HFD mice (Fig. 3A and B). Conversely, liraglutide treatment upregulated Bcl-2 and downregulated cleaved caspase-3 significantly (Fig. 3A and B). Furthermore, a significant increase was detected in the ratio of apoptotic cells in both the tubules and glomerulus of HFD-fed mice as compared to NC mice (Fig. 3C and D). After liraglutide treatment, the ratio of apoptotic cells in kidney of mice fed HFD also decreased significantly (Fig. 3C and D).

\section{Liraglutide reversed the protein expression of SIRT1 and TXNIP in HFD-induced kidney injury}

To test whether SIRT1 was involved in the beneficial effects of liraglutide on the kidney, the protein expression was detected by Western blotting. In the current study, the expression of SIRT1 in the HFD group was significantly lower than that in the NC group (Fig. 4). As expected, liraglutide treatment upregulated HFD-induced SIRT1 expression significantly (Fig. 4). Thioredoxininteracting protein (TXNIP), a pro-inflammatory, prooxidative stress, and pro-apoptotic protein plays a vital role in the onset and development of CKD (23, 24). Compared to the NC group, the protein level of TXNIP was significantly induced in the HFD group,

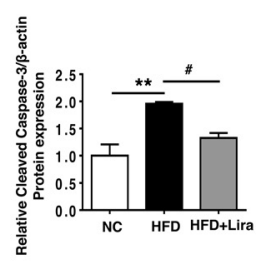

\section{Figure 3}

Liraglutide alleviated apoptosis in the kidney of HFD-fed mice. (A) Western blot analysis of $\mathrm{Bcl}-2$ and cleaved caspase-3 protein levels in different groups. (B) Ratios of $\mathrm{Bcl}-2$ to $\beta$-actin protein expression and cleaved caspase- 3 to $\beta$-actin protein expression were quantified in three independent experiments per condition. (C) Representative TUNEL staining of kidney tissue

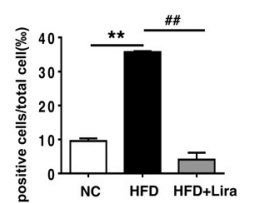
and an assay of the proportion of TUNEL-positive cells was performed using the Image-J software in six random fields for each mouse. Values are mean \pm S.E.M. $(n=3), * \star P<0.01$ NC vs HFD. ${ }^{\#} P<0.05$ HFD vs HFD + Lira; ${ }^{\#} P<0.01$ HFD vs HFD + Lira. Lira, liraglutide.

while the liraglutide administration remarkably downregulated the expression of TXNIP (Fig. 4).

\section{Liraglutide prevented apoptosis mediated by SIRT1 in HG-induced SV40 cells}

Next, we verified the above results in SV40 mouse mesangial cells in vitro. SV40 cells were exposed to $5.6 \mathrm{mmol} / \mathrm{L}(\mathrm{NG})$ or $30 \mathrm{mmol} / \mathrm{L}$ (HG) glucose with or without liraglutide for $48 \mathrm{~h}$. Consistent with the in vivo findings, the results showed a significant decrease in cleaved caspase- 3 protein expression in HG-challenged cells treated with liraglutide (10 and $100 \mathrm{nmol} / \mathrm{L})$ (Fig. 5A and B). Interestingly, liraglutide (100 nmol/L) significantly upregulated the expression of SIRT1 protein in HG-induced SV40 cells (Fig. 5A and B) compared to

A
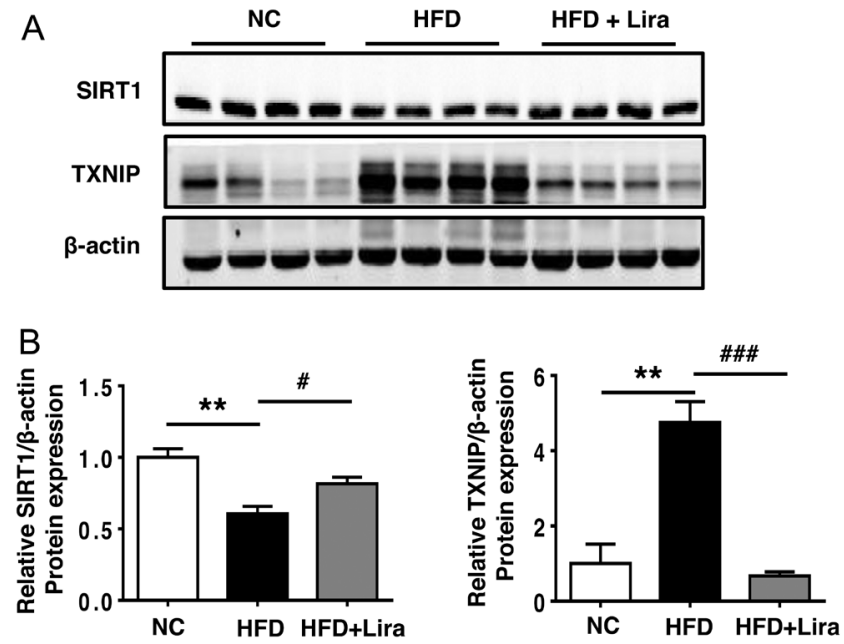

Figure 4

Liraglutide reversed the protein expression of SIRT1 and TXNIP in HFD-induced kidney injury. (A) Western blots analysis of SIRT1and TXNIP protein levels in different groups. (B) Ratios of SIRT1 to $\beta$-actin protein expression and TXNIP to $\beta$-actin protein expression were quantified in three independent experiments per condition. Data are expressed as the mean \pm S.E.M. $(n=4) .{ }^{*} p<0.01 \mathrm{NC}$ vs HFD. ${ }^{*} p<0.05$ HFD vs HFD + Lira; $\# \# P<0.001$ HFD vs HFD + Lira. Lira, liraglutide. 
A

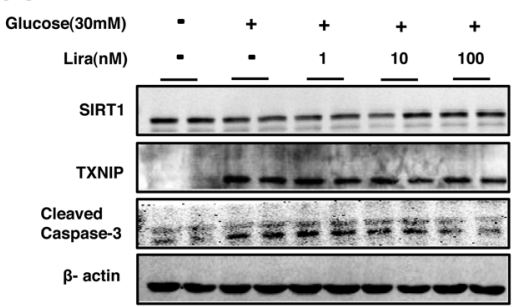

C

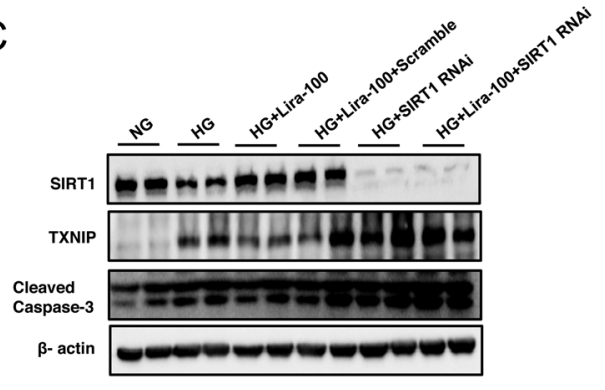

B
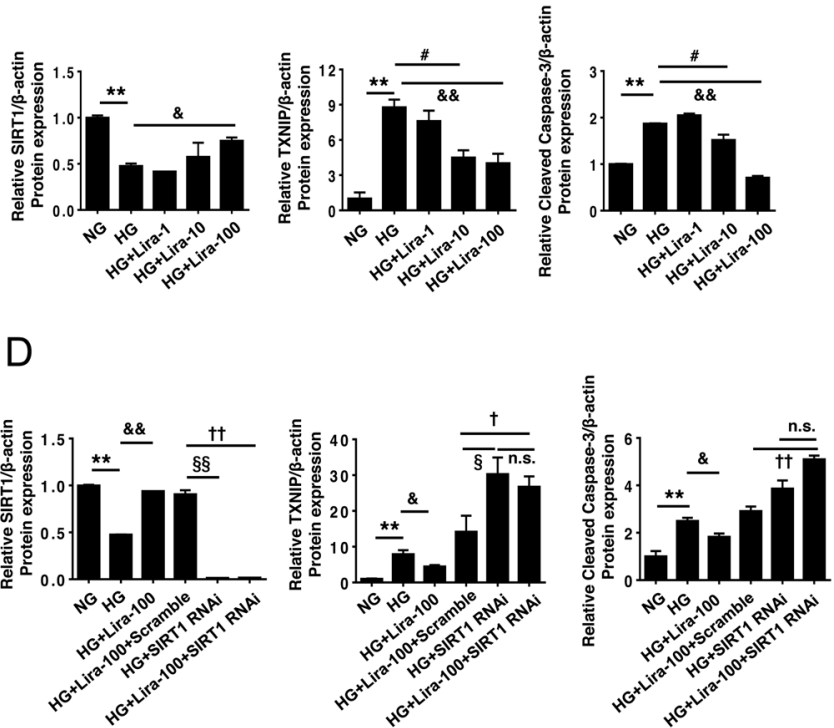

\section{Figure 5}

Liraglutide prevented apoptosis-induced RT1/TXNIP pathway in SV40 cells. (A) SV40 cells were treated with HG (30 mmol/L) with or without liraglutide $(1,10$, and $100 \mathrm{nmol} / \mathrm{L}$, respectively). SIRT1, TXNIP, and cleaved caspase-3 were detected. (B) Ratios of SIRT1 to $\beta$-actin, TXNIP to $\beta$-actin and cleaved caspase-3 to $\beta$-actin protein expressions were quantified in three independent experiments per condition. (C) Transfected SV40 cells were treated with HG (30 mmol/L) with or without liraglutide (100 nmol/L). SIRT1, TXNIP, and cleaved caspased-3 were detected. (D) Ratios of SIRT1 to $\beta$-actin protein, TXNIP to $\beta$-actin, and cleaved caspase-3 to $\beta$-actin protein expression were quantified in three independent experiments per condition. Data are expressed as

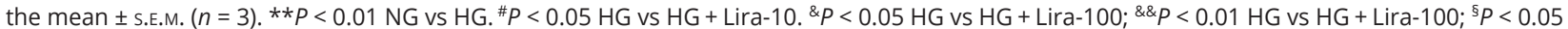
HG + Lira-100 + Scramble vs HG + SIRT1 RNAi; ${ }^{55} P<0.01 \mathrm{HG}+$ Lira-100+Scramble vs HG + SIRT1 RNAi. ${ }^{\dagger} P<0.05$ HG + Lira-100 + Scramble vs HG + Lira$100+$ SIRT1 RNAi; ${ }^{\dagger \dagger} P<0.01$ HG + Lira-100 + Scramble vs HG + Lira-100+SIRT1 RNAi. n.S., no significant difference. Lira, liraglutide; Lira-1: 1 nM liraglutide; Lira-10: 10 nM liraglutide; Lira-100: 100 nM liraglutide.

the HG group. We also found that liraglutide (10 and $100 \mathrm{nmol} / \mathrm{L}$ ) significantly decreased the expression of TXNIP protein compared to the HG group (Fig. 5A and B). After knocking down SIRT1 in SV40 cells, the above effects of liraglutide $(100 \mathrm{nmol} / \mathrm{L})$ on the decreased expression of cleaved caspase- 3 and TXNIP proteins were sharply blocked (Fig. 5C and D). These data supported that liraglutide downregulated the level of TXNIP and cleaved caspase-3 proteins to protect against HG-mediated apoptosis of SV40 cells via SIRT1.

\section{Discussion}

The obesity epidemic has led to an increased incidence of obesity-related renal damage $(25,26)$. Previous studies have demonstrated that weight loss contributes to a significant improvement in proteinuria and normalization of glomerular hyperfiltration in subjects with obesity (27). In this study, C57BL/6J mice fed on HFD developed obesity, hyperglycemia, and insulin resistance (Fig. 1). Elevated urinary ACR and pathological changes, which included glomerulomegaly, vacuolated tubular, thickened glomerular basement membrane, and tubulointerstitial fibrosis (Fig. 2), confirmed the establishment of a murine model to study obesity-related kidney disease. Hyperglycemia and hyperlipidemia activate apoptosis in animal and human podocytes, mesangial cells, and tubular cells $(20,26,28)$. Apoptosis was contributed to the pathophysiology of kidney injury $(29,30)$. The data demonstrated that HFD-fed mice and HG-incubated SV40 cells induce a significant increase in apoptotic cells and the expression of apoptosis markers, such as cleaved caspase- 3 and Bcl-2 (Figs 3, 5A and $\mathrm{B})$. Thus, we provided an insight into the putative mechanisms underlying obesity-related renal damage and albuminuria in order to find novel approaches to protect the kidney from damage at the early stage.

LEADER trial demonstrated that liraglutide improves the prognosis of renal damage in T2DM (12). However, the mechanism is yet poorly understood. Emerging evidence showed that the kidney protection of liraglutide is partially dependent on the improvements in control of blood glucose, blood pressure, blood lipid, and body https://ec.bioscientifica.com https://doi.org/10.1530/EC-20-0294 (c) 2020 The authors Published by Bioscientifica Ltd
This work is licensed under a Creative Commons Attribution-NonCommercial 4.0 International License. ded from Bioscientifica.com at 04/26/2023 10:19:48AM 
weight $(31,32,33)$. GLP-1 treatment suppresses the development of vacuolated tubular cells as compared to the HFD group (34). The current study demonstrated that liraglutide remarkably improved body weight and glucose homeostasis when administered once daily (Fig. 1). Moreover, treatment with liraglutide caused kidney weight loss and ameliorated 24-h urinary ACR as well as kidney morphology (Fig. 2). Also, some studies observed the glucose-independent effects on renal endpoint. In microalbuminuria patients with T2DM, treatment with exenatide reduced the urinary excretion of TGF $\beta 1$ and type IV collagen independent of glucose-lowering as compared to the glimepiride treatment group (35). Recent studies have shown that GLP-1R agonists exerted the reno-protective anti-inflammatory, anti-fibrosis, and anti-apoptosis effects, as well as reduction of reninangiotensin-aldosterone system (RASS) (13, 36, 37, 38). In the present study, we showed that liraglutide alleviated apoptosis in the kidney of HFD-induced mice and HG-mediated SV40 cells (Figs 3, 5A and B). However, the current data could not prove that liraglutideimproved renal function was secondary to the decline in renal damage risk factors, including reduced body weight and improved glucose homeostasis or attributed to the direct effect of GLP-1R in the kidney. GLP-1R stimulation stimulates cAMP and protein kinase A in kidney, which in turn, might result in reduced glomerular superoxide, renal NAD phosphate (NADPH) oxidase, and advanced glycation end products, further resulting in antiproliferation, anti-fibrosis, and anti-oxidant actions (39, 40). Next, we focused on SIRT1, a NAD (NAD $\left.{ }^{+}\right)$-dependent protein deacetylase. A study found that loss of SIRT1 led to severe apoptosis and fibrosis in the kidney in Sirt $1^{+/-}$ mice as compared to wild-type mice subjected to ureteral obstruction (17). In podocyte-specific Sirt1 knockout diabetic nephropathy mouse model, proteinuria increases significantly as compared to diabetic nephropathy mouse (41). Several studies have demonstrated that SIRT1 plays a positive role via the action of GLP-1 on maintaining glucose homeostasis $(42,43)$. The effect of exenatide on maintaining glucose homeostasis and improving insulin sensibility was attenuated in SIRT1 ${ }^{+/-}$mice fed with HFD (42). Liraglutide exerts a potent anti-inflammatory effect due to the inhibition of NF-кB pathway and upregulated level of SIRT1 in blood samples of patients with obesity and T2DM (43). Another study showed that SIRT1 and thioredoxin-interacting protein (TXNIP) have opposite effects on oxidative stress and metabolism in mediating the anti-aging interventions (44). TXNIP is recognized as a negative regulator of glucose metabolism and is triggered by diabetes and hyperglycemia $(24,45)$. TXNIPdeficient mice maintain both adipose and skeletal muscle insulin sensitivity when challenged with HFD (46). Recent in vitro data indicated that TXNIP mediates the hyperglycemia-mediated apoptotic death in pancreatic beta cells, skeletal muscle cells, and adipose cells (47). Recent studies have shown that GLP-1 agonists, such as exendin-4, reduce TXNIP levels, and thus, exert a protective effect against $\beta$-cell death $(48,49)$. However, the correlation between SIRT1 and TXNIP involved in GLP-1 treatment diabetes and the complications is yet to be established. In the current study, we examined whether the kidney protection effect of liraglutide is mediated by TXNIP through the activation of SIRT1. In vivo, the treatment with liraglutide upregulated the expression of SIRT1 and downregulated the expression of TXNIP proteins in the kidney of HFD-induced mice (Fig. 4). In vitro, after knocking down Sirt1, liraglutide treatment did not ameliorate the expression of TXNIP and cleaved caspase-3 proteins in HG-cultured SV40 cells (Fig. 5C and D). In vitro results supported that the glomerular anti-apoptosis effect of liraglutide might be mediated by SIRT1 through the downregulation of TXNIP.

In conclusion, we demonstrated that liraglutide, a GLP-1RA, protects against metabolism-related kidney damage and apoptosis, at least in part, by activation of the SIRT1 and suppression of TXNIP. Liraglutide might have a direct beneficial effect on CKD via this mechanism.

\section{Declaration of interest}

The authors declare that there is no conflict of interest that could be perceived as prejudicing the impartiality of the research reported.

\section{Funding}

This work was supported by the National Natural Science Foundation of China (81670762 to Mengyin Cai), the National Natural Science Foundation of China (81670782 to Fen Xu), the Natural Science Foundation of Guangdong Province (2016A030313258 to Mengyin Cai), the Science and Technology Program of Guangzhou, China (201707010118 to Mengyin Cai) and the Fundamental Research Funds for the Central Universities (13kypy31 to Mengyin Cai), Guangdong High-Level Talents Special Support Program (2016TQ03R590 to Fen Xu).

\section{Ethical approval}

Ethical approval was granted by the Animal Ethics Committees of the Sun Yat-Sen University - (Reference No- IACUC-F3-17-0801).

\section{Author contribution statement}

$\mathrm{R} L$ carried out experiments, interpreted data, and wrote manuscript. $\mathrm{M} \mathrm{W}$ and C F carried out experiments. H L, H D and $Y T$ contributed to the data 
analysis and revision of the manuscript. F X and M C contributed to the study design and revising and editing the manuscript.

\section{References}

1 Lin TY, Liu JS \& Hung SC. Obesity and risk of end-stage renal disease in patients with chronic kidney disease: a cohort study. American Journal of Clinical Nutrition 2018108 1145-1153. (https://doi. org/10.1093/ajcn/nqy200)

2 Zhang L, Long J, Jiang W, Shi Y, He X, Zhou Z, Li Y, Yeung RO, Wang J, Matsushita K, et al. Trends in chronic kidney disease in China. New England Journal of Medicine 2016375 905-906. (https:// doi.org/10.1056/NEJMc1602469)

3 Whaley-Connell A \& Sowers JR. Obesity and kidney disease: from population to basic science and the search for new therapeutic targets. Kidney International 201792 313-323. (https://doi. org/10.1016/j.kint.2016.12.034)

4 de Vries APJ, Ruggenenti P, Ruan XZ, Praga M, Cruzado JM, Bajema IM, D'Agati VD, Lamb HJ, Barlovic DP, Hojs R, et al. Fatty kidney: emerging role of ectopic lipid in obesity-related renal disease. Lancet: Diabetes and Endocrinology 20142 417-426. (https://doi. org/10.1016/S2213-8587(14)70065-8)

5 D'Agati VD, Chagnac A, de Vries AP, Levi M, Porrini E, HermanEdelstein M \& Praga M. Obesity-related glomerulopathy: clinical and pathologic characteristics and pathogenesis. Nature Reviews: Nephrology 201612 453-471. (https://doi.org/10.1038/nrneph.2016.75)

6 Serra A, Romero R, Lopez D, Navarro M, Esteve A, Perez N, Alastrue A $\&$ Ariza A. Renal injury in the extremely obese patients with normal renal function. Kidney International 200873 947-955. (https://doi. org/10.1038/sj.ki.5002796)

7 Panwar B, Hanks LJ, Tanner RM, Muntner P, Kramer H, McClellan WM, Warnock DG, Judd SE \& Gutierrez OM. Obesity, metabolic health, and the risk of end-stage renal disease. Kidney International 201587 1216-1222. (https://doi.org/10.1038/ ki.2014.384)

8 Cho YM, Fujita Y \& Kieffer TJ. Glucagon-like peptide-1: glucose homeostasis and beyond. Annual Review of Physiology 201476 535-559. (https://doi.org/10.1146/annurev-physiol-021113-170315)

9 Jensen EP, Poulsen SS, Kissow H, Holstein-Rathlou NH, Deacon CF, Jensen BL, Holst JJ \& Sorensen CM. Activation of GLP-1 receptors on vascular smooth muscle cells reduces the autoregulatory response in afferent arterioles and increases renal blood flow. American Journal of Physiology: Renal Physiology 2015308 F867-F877. (https://doi. org/10.1152/ajprenal.00527.2014)

10 Pyke C, Heller RS, Kirk RK, Orskov C, Reedtz-Runge S, Kaastrup P, Hvelplund A, Bardram L, Calatayud D \& Knudsen LB. GLP-1 receptor localization in monkey and human tissue: novel distribution revealed with extensively validated monoclonal antibody. Endocrinology 2014 155 1280-1290. (https://doi.org/10.1210/en.2013-1934)

11 Schlatter P, Beglinger C, Drewe J \& Gutmann H. Glucagonlike peptide 1 receptor expression in primary porcine proximal tubular cells. Regulatory Peptides 2007141 120-128. (https://doi. org/10.1016/j.regpep.2006.12.016)

12 Mann JFE, Orsted DD, Brown-Frandsen K, Marso SP, Poulter NR, Rasmussen S, Tornoe K, Zinman B, Buse JB \& LEADER Steering Committee and Investigators. Liraglutide and renal outcomes in Type 2 diabetes. New England Journal of Medicine 2017377 839-848. (https://doi.org/10.1056/NEJMoa1616011)

13 Muskiet MHA, Tonneijck L, Smits MM, van Baar MJB, Kramer MHH, Hoorn EJ, Joles JA \& van Raalte DH. GLP-1 and the kidney: from physiology to pharmacology and outcomes in diabetes. Nature Reviews: Nephrology 201713 605-628. (https://doi.org/10.1038/ nrneph.2017.123)

14 Katsyuba E, Mottis A, Zietak M, De Franco F, van der Velpen V, Gariani K, Ryu D, Cialabrini L, Matilainen O, Liscio P, et al. De novo
$\mathrm{NAD}(+)$ synthesis enhances mitochondrial function and improves health. Nature 2018563 354-359. (https://doi.org/10.1038/s41586018-0645-6)

15 Guan Y \& Hao CM. SIRT1 and kidney function. Kidney Disease 2015 1 258-265. (http://doi.org/10.1159/000440967)

16 Wakino S, Hasegawa K \& Itoh H. Sirtuin and metabolic kidney disease. Kidney International 201588 691-698. (https://doi. org/10.1038/ki.2015.157)

17 He W, Wang Y, Zhang MZ, You L, Davis LS, Fan H, Yang HC, Fogo AB, Zent R, Harris RC, et al. Sirt1 activation protects the mouse renal medulla from oxidative injury. Journal of Clinical Investigation 2010120 1056-1068. (https://doi.org/10.1172/JCI41563)

18 Hasegawa K, Wakino S, Simic P, Sakamaki Y, Minakuchi H, Fujimura K, Hosoya K, Komatsu M, Kaneko Y, Kanda T, et al. Renal tubular Sirt1 attenuates diabetic albuminuria by epigenetically suppressing Claudin-1 overexpression in podocytes. Nature Medicine 201319 1496-1504. (https://doi.org/10.1038/nm.3363)

19 Kundu A, Richa S, Dey P, Kim KS, Son JY, Kim HR, Lee SY, Lee BH, Lee KY, Kacew S, et al. Protective effect of EX-527 against high-fat diet-induced diabetic nephropathy in Zucker rats. Toxicology and Applied Pharmacology 2020390 114899. (https://doi.org/10.1016/j. taap.2020.114899)

20 Qi W, Keenan HA, Li Q, Ishikado A, Kannt A, Sadowski T, Yorek MA, Wu IH, Lockhart S, Coppey LJ, et al. Pyruvate kinase M2 activation may protect against the progression of diabetic glomerular pathology and mitochondrial dysfunction. Nature Medicine 201723 753-762. (https://doi.org/10.1038/nm.4328)

21 Hotchkiss RS, Strasser A, McDunn JE \& Swanson PE. Cell death. New England Journal of Medicine 2009361 1570-1583. (https://doi. org/10.1056/NEJMra0901217)

22 Man SM\& Kanneganti TD. Converging roles of caspases in inflammasome activation, cell death and innate immunity. Nature Reviews: Immunology 201616 7-21. (https://doi.org/10.1038/nri.2015.7)

23 Kumar A Mittal R. Mapping Txnip: key connexions in progression of diabetic nephropathy. Pharmacological Reports 201870 614-622. (https://doi.org/10.1016/j.pharep.2017.12.008)

24 Zhou R, Tardivel A, Thorens B, Choi I \& Tschopp J. Thioredoxininteracting protein links oxidative stress to inflammasome activation. Nature Immunology 201011 136-140. (https://doi. org/10.1038/ni.1831)

25 Deji N, Kume S, Araki S, Soumura M, Sugimoto T, Isshiki K, ChinKanasaki M, Sakaguchi M, Koya D, Haneda M, et al. Structural and functional changes in the kidneys of high-fat diet-induced obese mice. American Journal of Physiology: Renal Physiology 2009296 F118-F126. (https://doi.org/10.1152/ajprenal.00110.2008)

26 Szeto HH, Liu S, Soong Y, Alam N, Prusky GT \& Seshan SV. Protection of mitochondria prevents high-fat diet-induced glomerulopathy and proximal tubular injury. Kidney International 201690 997-1011. (https://doi.org/10.1016/j.kint.2016.06.013)

27 Macumber IR. Improving kidney disease in obese adolescents: a surgical approach. Kidney International 201791 279-281. (https://doi. org/10.1016/j.kint.2016.10.024)

28 Feng H, Gu J, Gou F, Huang W, Gao C, Chen G, Long Y, Zhou X, Yang M, Liu S, et al. High glucose and lipopolysaccharide prime NLRP3 inflammasome via ROS/TXNIP pathway in mesangial cells. Journal of Diabetes Research 20162016 6973175. (https://doi. org/10.1155/2016/6973175)

29 Brezniceanu ML, Lau CJ, Godin N, Chenier I, Duclos A, Ethier J, Filep JG, Ingelfinger JR, Zhang SL \& Chan JS. Reactive oxygen species promote caspase-12 expression and tubular apoptosis in diabetic nephropathy. Journal of the American Society of Nephrology 201021 943-954. (https://doi.org/10.1681/ASN.2009030242)

30 Sifuentes-Franco S, Padilla-Tejeda DE, Carrillo-Ibarra S \& MirandaDiaz AG. Oxidative stress, apoptosis, and mitochondrial function in diabetic nephropathy. International Journal of Endocrinology 2018 2018 1875870. (https://doi.org/10.1155/2018/1875870)

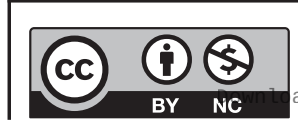


31 Smits MM, Tonneijck L, Muskiet MH, Kramer MH, Cahen DL \& van Raalte DH. Gastrointestinal actions of glucagon-like peptide-1-based therapies: glycaemic control beyond the pancreas. Diabetes, Obesity and Metabolism 201618 224-235. (https://doi.org/10.1111/dom.12593)

32 Sun F, Wu S, Guo S, Yu K, Yang Z, Li L, Zhang Y, Quan X, Ji L \& Zhan S. Impact of GLP-1 receptor agonists on blood pressure, heart rate and hypertension among patients with type 2 diabetes: a systematic review and network meta-analysis. Diabetes Research and Clinical Practice 2015110 26-37. (https://doi.org/10.1016/j. diabres.2015.07.015)

33 Kanoski SE, Hayes MR \& Skibicka KP. GLP-1 and weight loss: unraveling the diverse neural circuitry. American Journal of Physiology: Regulatory, Integrative and Comparative Physiology 2016310 R885-R895. (https://doi.org/10.1152/ajpregu.00520.2015)

34 Guo H, Li H, Wang B, Ding W, Ling L, Yang M, Gu Y \& Niu J. Protective effects of glucagon-like peptide-1 analog on renal tubular injury in mice on high-fat diet. Cellular Physiology and Biochemistry 201741 1113-1124. (https://doi.org/10.1159/000464118)

35 Zhang H, Zhang X, Hu C \& Lu W. Exenatide reduces urinary transforming growth factor-beta 1 and type IV collagen excretion in patients with type 2 diabetes and microalbuminuria. Kidney and Blood Pressure Research 201235 483-488. (https://doi. org/10.1159/000337929)

36 Kodera R, Shikata K, Kataoka HU, Takatsuka T, Miyamoto S, Sasaki M, Kajitani N, Nishishita S, Sarai K, Hirota D, et al. Glucagon-like peptide-1 receptor agonist ameliorates renal injury through its antiinflammatory action without lowering blood glucose level in a rat model of type 1 diabetes. Diabetologia 201154 965-978. (https://doi. org/10.1007/s00125-010-2028-x)

37 Inoue T, Inoguchi T, Sonoda N, Hendarto H, Makimura H, Sasaki S, Yokomizo H, Fujimura Y, Miura D \& Takayanagi R. GLP-1 analog liraglutide protects against cardiac steatosis, oxidative stress and apoptosis in streptozotocin-induced diabetic rats. Atherosclerosis 2015 240 250-259. (https://doi.org/10.1016/j.atherosclerosis.2015.03.026)

38 Wei J, Wu H, Zhang H, Li F, Chen S, Hou B, Shi Y, Zhao L \& Duan H. Anthocyanins inhibit high glucose-induced renal tubular cell apoptosis caused by oxidative stress in $\mathrm{db} / \mathrm{db}$ mice. International Journal of Molecular Medicine 201841 1608-1618. (https://doi. org/10.3892/ijmm.2018.3378)

39 Ishibashi Y, Matsui T, Ojima A, Nishino Y, Nakashima S, Maeda S \& Yamagishi S. Glucagon-like peptide-1 inhibits angiotensin II-induced mesangial cell damage via protein kinase A. Microvascular Research 201284 395-398. (https://doi.org/10.1016/j.mvr.2012.06.008)

40 Hendarto H, Inoguchi T, Maeda Y, Ikeda N, Zheng J, Takei R, Yokomizo H, Hirata E, Sonoda N \& Takayanagi R. GLP-1 analog liraglutide protects against oxidative stress and albuminuria in streptozotocin-induced diabetic rats via protein kinase A-mediated inhibition of renal NAD $(\mathrm{P}) \mathrm{H}$ oxidases. Metabolism: Clinical and Experimental 201261 1422-1434. (https://doi.org/10.1016/j. metabol.2012.03.002)

41 Liu R, Zhong Y, Li X, Chen H, Jim B, Zhou MM, Chuang PY \& He JC. Role of transcription factor acetylation in diabetic kidney disease. Diabetes 201463 2440-2453. (https://doi.org/10.2337/db13-1810)

$42 \mathrm{Xu} \mathrm{F}$, Li Z, Zheng X, Liu H, Liang H, Xu H, Chen Z, Zeng K \& Weng J. SIRT1 mediates the effect of GLP-1 receptor agonist exenatide on ameliorating hepatic steatosis. Diabetes 201463 3637-3646. (https:// doi.org/10.2337/db14-0263)

43 Savchenko LG, Digtiar NI, Selikhova LG, Kaidasheva EI, Shlykova OA, Vesnina LE \& Kaidashev IP. Liraglutide exerts an anti-inflammatory action in obese patients with type 2 diabetes. Romanian Journal of Internal Medicine 201957 233-240. (https://doi. org/10.2478/rjim-2019-0003)

44 Mousa SA, Gallati C, Simone T, Dier E, Yalcin M, Dyskin E, Hanko C \& Rebbaa A. Dual targeting of the antagonistic pathways mediated by Sirt1 and TXNIP as a putative approach to enhance the efficacy of anti-aging interventions. Aging 2009 1 412-424. (http://doi. org/10.18632/aging.100035)

45 De Marinis Y, Cai M, Bompada P, Atac D, Kotova O, Johansson ME, Garcia-Vaz E, Gomez MF, Laakso M \& Groop L. Epigenetic regulation of the thioredoxin-interacting protein (TXNIP) gene by hyperglycemia in kidney. Kidney International 201689 342-353. (https://doi.org/10.1016/j.kint.2015.12.018)

46 Chutkow WA, Birkenfeld AL, Brown JD, Lee HY, Frederick DW, Yoshioka J, Patwari P, Kursawe R, Cushman SW, Plutzky J, et al. Deletion of the alpha-arrestin protein Txnip in mice promotes adiposity and adipogenesis while preserving insulin sensitivity. Diabetes 201059 1424-1434. (https://doi. org/10.2337/db09-1212)

47 Thielen L\& Shalev A. Diabetes pathogenic mechanisms and potential new therapies based upon a novel target called TXNIP. Current Opinion in Endocrinology, and Diabetes and Obesity 201825 75-80. (http://doi.org/10.1097/MED.000000000000039)

48 Chen J, Couto FM, Minn AH \& Shalev A. Exenatide inhibits beta-cell apoptosis by decreasing thioredoxin-interacting protein. Biochemical and Biophysical Research Communications 2006346 1067-1074. (https://doi.org/10.1016/j.bbrc.2006.06.027)

49 Shao W, Yu Z, Fantus IG \& Jin T. Cyclic AMP signaling stimulates proteasome degradation of thioredoxin interacting protein (TxNIP) in pancreatic beta-cells. Cellular Signalling 201022 1240-1246. (https://doi.org/10.1016/j.cellsig.2010.04.001)

Received in final form 13 August 2020

Accepted 3 September 2020

Accepted Manuscript published online 4 September 2020 https://ec.bioscientifica.com https://doi.org/10.1530/EC-20-0294 (c) 2020 The authors Published by Bioscientifica Ltd

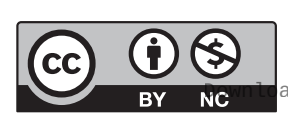

This work is licensed under a Creative Commons Attribution-NonCommercial 4.0 International License. ded from Bioscientifica.com at 04/26/2023 10:19:48AM 